\title{
Sporadic Thyroid Gland Medullary
}

\section{Carcinoma}

National Cancer Institute

\section{Source}

National Cancer Institute. Sporadic Thyroid Gland Medullary Carcinoma. NCI Thesaurus. Code C46098.

A non-hereditary medullary carcinoma of the thyroid gland not associated with multiple endocrine neoplasia. The majority of thyroid gland medullary carcinomas are sporadic. 